\title{
The method of low power consumption sediment transport for the
}

\section{environmental dredging}

\author{
Hucheng $\mathrm{LI}^{1 \mathrm{a}}$, Bingbing WANG ${ }^{2 b}$, Jun YAN², Liuming WAN ${ }^{2}$, Fei ZHUO \\ ${ }^{1}$ GuangDong Research Institute of Water Resources and Hydropower, Guangzhou, 510635 \\ ${ }^{2}$ North China University of Water Resources and Electric Power, Zhengzhou, 450011 \\ a77045159@qq.com, bsy2009wangbing@163.com
}

Keywords: the environmental dredging; ecological environment; Low-power consumption

Abstract: With the deepening of the concept of environmental protection, the problem of environmental protection is becoming more and more prominent. In the operation of the waterway dredging project, the premise is protecting the environment. Avoid the adverse effects of the various channel dredging technology on the environment, a low power pneumatic sediment dredging system is proposed, which mainly depends on air pump to disturb and transport sediment by solar energy. It can not only improve the water channel, but also reduce the adverse impact on the environment.

\section{Introduction}

With the rapid development of economy and society, human activities have gradually expanded and the ability of human to change nature has also improved. Meanwhile, the ecological environment has caused great destruction and brought negative influence to people's life. Only by realizing the synchronous development of environment and economy can we really promote the society and enhance people's quality of life. Shipping plays an important role in people's life, and it is necessary to carry out the port channel dredging under the premise of environmental protection. Because of the weak environmental protection consciousness, all kinds of industrial waste, urban and rural domestic sewage and chemical fertilizer pesticide residue of agricultural production with a little or no treatment are directly discharged into rivers and lakes, causing the water polluted. At present, water environmental pollution in China is very serious, such a wide range of the pollution area, kinds and affected area can not be ignored.

Environmental dredging is a new industry developing in recent years, which combines characteristics of environmental engineering, water conservancy projects, and dredging engineering technical. It demands the construction technology which has little influence on the nearby water by using the method of mechanical dredging to remove contaminated sediments in rivers and lakes to achieve the purpose of dredging channel and causing little damage to the surrounding ecological environment.

\section{The current status of waterway dredging project in China}

The advantages and disadvantages of current waterway dredging. At present, the common dredging technology is high-pressure water jet thrust to stir sediment, blast disturbance, mud pump and suction disturbance operations. Because the rushed up sediments are chosen after a long time, long distance, when washed and stirred again, making the sand bed difficult to realize fully 
suspended sediment, except fine sand. The stirring of the blasting has a certain risk, and needs high construction precision, which will endanger the safety of the dam and the river bank, while the harmful gas generated by explosion will damage the ecological environment of the river. Pump suction disturbance and harassing operations are both using mechanical power to intake sediment and then spray it to the water. Sand disturbance efficiency is high, but it needs to spend a lot of manpower, finance and resources which will produce waste residue, waste gas and noise pollution in construction process, causing different degrees of damage on the ecological environment.

The influence of dredging project on the ecological environment in China. For China's waterway dredging project, the large-scale modernization of equipment for processing sand water environment is used. Therefore, many aspects impact on the ecological environment in the process of construction.

(1) In normal circumstances, the natural water has the ability of self adjustment and dilution, so the turbidity of the water can be maintained for a long time in the absence of external interference. And it will not affect the growth of aquatic organisms in the water ${ }^{[1]}$. However, the work of port waterway dredging often produces a large number of inorganic suspended solids, breaking the balance of the water's turbidity and leading to a rapid increase in the turbidity of the water. After a period of time, these inorganic suspended solids will sink, and bury the water life in the water, affecting its normal growth and reproduction and destroying the ecological balance.

(2) While dredger, disturbance sand ships and other large tonnage ships are in dock or sailing, oil leakage is inevitable at the bottom of the cabin. Although the oil leakage problem is a normal phenomenon in the case of two kinds of liquid contact, it will not have a huge effect on the ship's navigation and safety performance. The pollution of the area around the channel is more serious, which inhibits the growth of water aquatic organisms, pollute water and water environment.

(3) In the construction process of the port channel dredging, especially in the stemming operation, a very large noise will occur in the process of dredging construction work. Generally speaking, noise pollution has little effect on plants, but has large effect on animals ${ }^{[2]}$. Fish in this area tend to die, suffering high frequency noise which makes deadly impact on the physiological circulation system of fish. Or a large number of fish migrate, thus the waters become a backwater, breaking the balance of ecological environment of the waters.

(4) At present, the blasting technology has been quite mature, which can be used in the river to carry out the sediment transport. Its basic principle is using blasting can release huge energy in a short period of time, which combines the reservoir operation, through the careful design of underwater blasting, blasting out of the narrow and deep channel. Meanwhile, the silt sand is mixed with water to increase the flow of the suspended sediment concentration and form the best flow section, the best plane form and the best water and sediment distribution, to achieve the greatest efficiency of sediment ${ }^{[3]}$. But considering the environment protection, the blasting technology has a certain influence on the ecological environment and the river itself. First, the blasting has a certain risk and needs high construction accuracy. The safety of the dam and the river bank will be endangered by careless construction, especially the structure of the river bottoms. Second, the harmful gas blasting causes damage to the ecological environment of the river, so as to the waste residue, waste gas and noise pollution in the construction process.

\section{New environmental dredging technique}

\section{Eco-friendly dredging technology}

Eco-friendly dredging is the combination of the transport, digging with water conservation, ecological restoration, environmental management and resource utilization in the dredging project. 
Through comprehensive management, it finally achieves double goals to remove the inner source of lake pollution and create favorable conditions for ecological restoration. The pollution sources in lakes can be removed based on the dredging project, so as in channel and the river ${ }^{[4]}$. Usually the environmental dredging projects include the construction of the yard, dredging and transport of sediment, sediment dehydration, treatment of residual water to reach the standard, recovery, utilization, and restoration of the yard, etc.

Environmental dredging is a complicated engineering system. Preparation work needs high accuracy of survey, many borehole fields, and large proportion of mapping. In addition to the conventional physical and mechanical indexes, the chemical analysis of a number of laboratory contaminants is also needed to determine the types, quantities and distribution of major pollutants to assess the impact of pollutants on the environment and to provide the basis for the environmental dredging. The design work needs the accurate survey, measurement and the pollutant analysis for the reasonable economic construction methods and the construction ship types. It requires a high precision so the dredging equipment must be equipped with special devices and measures preventing the spread and leakage in order to ensure the effective removal of contaminated sediment without causing the water and the secondary pollution of environment. The removed contaminated sediment should be treated appropriately to avoid new damage and threat to the surrounding environment.

\section{Low power pneumatic sediment dredging system}

In order to overcome the great energy consumption of the existing channels, reduce the use of non-renewable energy, a new technology of environmental dredging is proposed, which is named as the low power pneumatic sediment dredging system, as shown in fig.1. Mainly solar power is used to drive the gas pump into river bed for interference, blowing sand and clean out the channel. The advantages of this low power pneumatic transport sand technology are as follows:

(1) Using the solar power generation to drive part of the system. The solar energy is a renewable clean energy, the development and utilization of solar energy will not pollute the environment, especially for the serious environmental pollution currently. The solar energy takes places of coal, oil and other non-renewable energy, avoiding air pollution caused by toxic and harmful gas of coal, oil incomplete burning.

(2) Simple and easy operation of the new structure. The ship is fixed on the horizontal plane of the river by means of an anchor, and by changing the position of the ship in the horizontal plane, it has a wide range of popularization and can work on the river for a long time with the sun, which is suitable for large-scale.

(3) Pneumatic sediment dredging system is based on the principle that air in the water will go up due to light density. During the process, the rising flow is produced to drive up silt into water, making the sediment be transmitted over a long distance. The finer sediment particle size is, the smaller settling velocity is. The better the effect of scouring and silting in pneumatic is, the more obvious effects in the fine grained sediment river are. In the governance of the Yellow River, this method can save energy and transport sand over long distance. After riverbed is buried with pipe, tube will not be jam, for the compressed air can flow the sand and silt actively. During air flushes the sediment, it can keep on flushing a lot of sand, and cause less damage to the channel bottom structure. Compared with other river dredging technology, the impact on the environment is lest. 


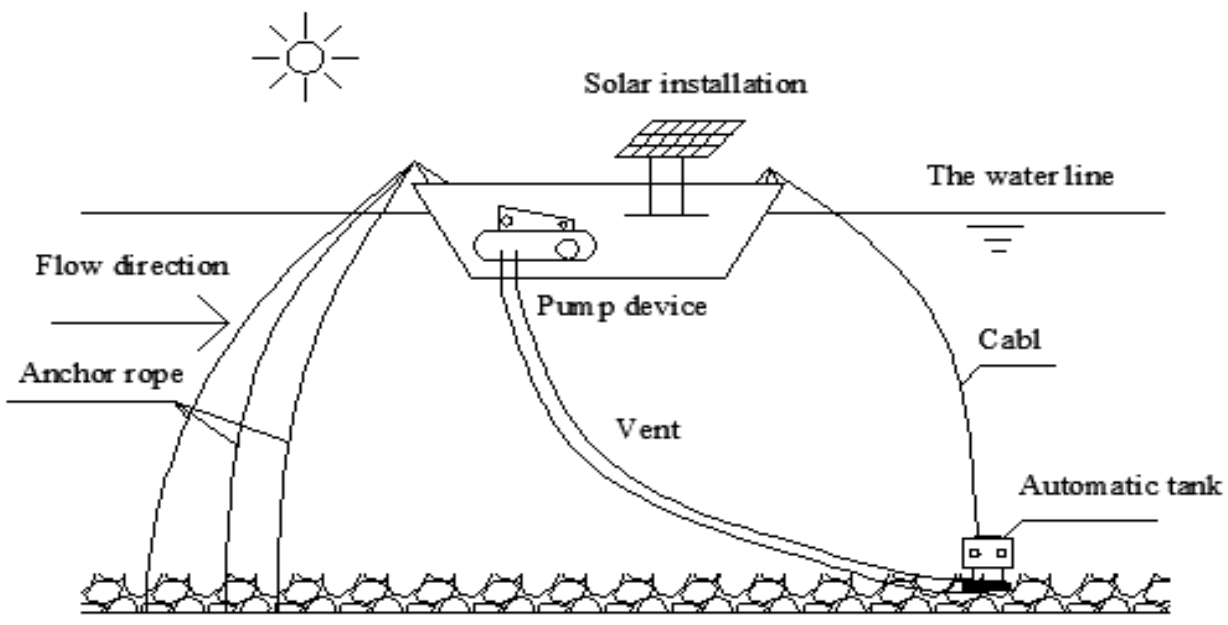

Fig. 1 Structure of the low power consumption pneumatic conveying device

Fig. 1 is working diagram for the low power consumption of pneumatic conveying device, composed of small motor boats, solar device, pump, hose, automatic water tank and horn nozzle. Small motor boats are fixed on the river by a few anchors. The small motor boat is provided with a solar device, and pump operation is driven by solar power, ventilation pipe connected with the air pump and nozzle in the river. An automatic tank is fixed above the trumpet nozzle, and the height of the horn nozzle can be adjusted by changing the proportion of water and air in the water tank. The position of the small motor boat can be changed by adjusting the anchor position. The nozzle at the bottom of the horn can be adjusted by using the automatic tank, acting on the river flow and sediment for dredging.

This low power pneumatic transport system has wide application, for it is suitable for reservoir dredging and river regulation in non-canyon areas, such as river, lake, with abundant solar energy, and ports, docks and tap water plant water intake dredging. But for rivers with many clouds the effectiveness of solar panels will be reduced. A battery on the boat is recommended, making the battery full of electricity in case of no sunlight or in the darkness.

\section{Summary}

Under the premise of the ecological environment protection, strengthening the protection of the environment is very necessary. In China, the environmental dredging technology can accomplish the purpose of dredging the river, but it will cause a certain degree of damage to the surrounding aquatic ecosystem. Based on environmental protection concept, a low power consumption and sediment transport and sediment dredging system is introduced, both to achieve the purpose of dredging the channel and low energy consumption, less pollution to the environment.

\section{Acknowledgements}

This work was financially supported by the Water conservancy science and technology innovation project of Guangdong province in 2011(2011-21).

\section{Reference}

[1] LIAN Zm., LIU X., Study on the dredging projects concerning the environmental protection [J]. Engineering technology, 2012(15), p. 71-73. 
[2] YAN Ch., FAN Cx., YANG Jh., Prospect of the study on the environmental dredging technology for sediment in lake [J]. Environmental pollution \& control, 2004(03), p.189-192.

[3] ZHAO Sg., LIN Xz., JIANG Eh., Application of blasting disturbance sediment technology in the test of water and sediment regulation in lower reaches of Yellow River [J]. Engineering blasting, 2005(04), p.5-8.

[4] LUO Y., DOU Xp., LUO Zs., Thinking for the sediment regulation with "air-uplift" in the Yellow River [J]. Journal of Hydraulic Engineering, 2007 (S1): p.276-282. 